\title{
ETV6/RUNX1 Fusion Protein
}

National Cancer Institute

\section{Source}

National Cancer Institute. ET V6/RUNX1 Fusion Protein. NCI Thesaurus. Code C18040.

A fusion protein encoded by the ETV6/RUNX1 fusion gene. This protein is comprised of the N-terminal DNA binding helix-loop-helix domain of the transcription factor ETV6 protein fused to nearly the entire runt-related transcription factor 1 protein. 